\title{
Why do we take care of others? A proposal
}

\author{
E. Parravicini
}

Published online: 6 April 2010

(c) Springer-Verlag 2010

There is a growing dissatisfaction among health care professionals. This is a time of crisis in which the very nature of the medical art is at risk because the concept of the person is confused. In fact, in current medical practice, the core of the medical profession, which is the relationship between patient and caregiver, has been turned into a sort of mechanism, and our own practice is heavily influenced by this mentality. The evaluation of a patient has been reduced to the mere identification of abnormal physical or psychical mechanisms; the patients themselves are treated as very complex organic mechanisms; the treatment plan is the communication of different options to a patient, left alone to decide. As summarized by JD Cantor [1], the caregiver is envisioned as a "neutral arbiter of medical care" of patients whose only needs seem to be "information, referrals and treatment".

This approach in medical practice is rooted in a concept of a person restricted to his/her biological factors, which is profoundly inadequate. When confronted with illness, pain and death, both patients and caregivers face

E. Parravicini (西)

Department of Pediatrics

3959 Broadway, CHN 1213

New York, NY 10032, USA

e-mail: ep127@columbia.edu critical questions such as: What is the meaning of this illness? Why is there pain and death? These questions reawaken the recognition that the person is not completely defined by his or her biology. In addition to attentive evaluation, accurate diagnosis, reliable prognostic assessment and use of appropriate treatment of an illness, we need to know its meaning.

The painting "The Fall of Icarus" by Marc Chagall (see picture) is somehow emblematic of this issue. Icarus, a brave man who wanted to fly too close to the sun, plunged to the ground as his wax wings melted. Icarus represents the nature of the human being, which is desire, and yet has inexorable limitations: suffering and sickness are unavoidable and ultimately are the premonition of death. Chagall depicts the fall Icarus welcome by the people of the town with open arms, with tenderness and compassion. In history, care for the sick came about this way, through people moved with compassion and willingness to share the same limitations and the same desire.

We, as caregivers, are part of this crowd. Whoever pursued his/her carrier in the medical field, somehow did so for a desire to serve people in need. Thus, medical professionals must attempt to identify motivations strong enough for providing medical care. Health care addresses people and their needs. Technical competence is not enough, as G.C. Cesana says in his invited paper published in this issue of the journal: 'Doctors are not veterinaries, and not because they deal with more complex animals, but because they do not deal with animals at all. They deal with human beings, who search for the meaning of their suffering, the link between their life and destiny. Sickness is the sign that the definitive meaning of things and ourselves, if it exists, is greater than us. An illness is a warning, the last and most terrible warning, 


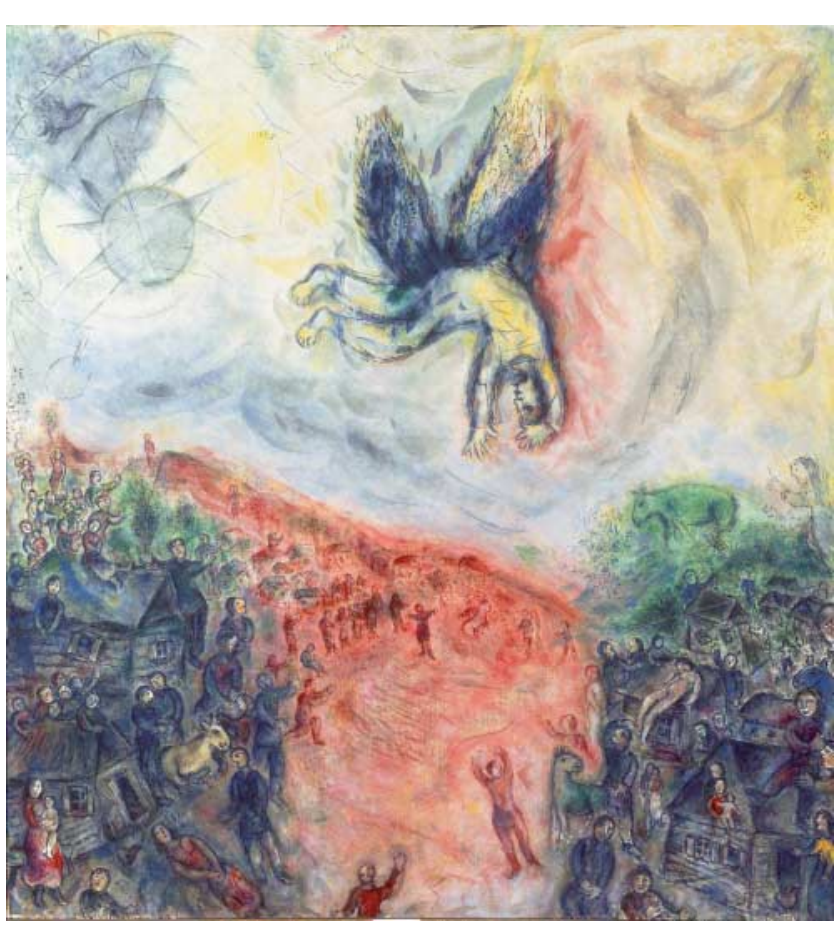

prompting a search for this meaning' [2]. Therefore, medical care should focus on the needs of patients, including the need to be healed and the need to find a meaning for their suffering. Practicing medical care where the diagnosis and treatment of physical illnesses are not separated from the questions of meaning is indeed possible, and it makes a difference in medical practice.

This was the main theme of the 2009 MedConference, held on June 12-14 at the Hyatt on the Hudson, Jersey City, NJ and titled "Why do we take care of others? A proposal," (http://www.medicalconference.us/). Two of the main talks presented in that conference are published in this journal issue [2, 3]. The Conference opened with a piano concert, entitled "An Unexpected Beauty within Sorrow". Christopher Vath played the Sonata in B-flat major D. 960 by F. Schubert, and other works by Chopin, Ravel and Bach. What does music have to do with medical care? The organizers hold that classical music communicates, together with beauty, a deep nostalgia, a sense that life is not complete yet. Thus, the audition of music was proposed as an instrument for the audience to perceive the depth of the human heart and to facilitate the familiarity with a level in the person that is too often ignored.

In his paper [2], G.C. Cesana explores, through a short outline of the history of medicine, the root of the current crisis in health care and documents the longing for a meaning in illness and suffering. Moreover, he propose that, while 'medical care was born out of a positive and meaningful approach [...] the difficulty is our weakness in following such an impulse, in particular when a sacrifice is required [...] medicine calls us to rebuild humanity from the great limit, represented by diseases and from others more subtle, such as our limits in intelligence and morality. A doctor or a nurse cannot but search for a place, a context, in which such a continuous rebuilding is possible'.

D.P. Sulmasy highlights in his paper [3] that realism is mandatory in ethics. "While ethics is a very important aspect of medical care [...] reality comes before ethics. [...] Medical ethics is rooted in the encounter that one free human person (the clinician) has with the reality of another human person (the patient), whose freedom is limited by the stark realities of illness, injury, and death. Attending to the cry of the real is the surest road to truly good medical care' [3].

These contributions describe in different ways that the only adequate motivation for taking care of patients is "putting the heart in the profession", where the word "heart" indicates the "original impetus with which the human being reaches out to reality, seeking to become one with it through the implementation of projects dictated by the ideal" [4]. This approach of medical care, rooted in attentiveness towards patients and their conditions and the search for a meaning, generates professional success and patient satisfaction, documented by moments of unexpected beauty, regardless of the final outcome.

\section{References}

1. Cantor JD (2009) Conscientious objection gone awry - restoring selfless professionalism in medicine. $N$ Engl $J$ Med 360:1484-1485

2. Cesana GC (2010) Hope and care. J Med Pers 8:9-14

3. Sulmasy DP (2010) Ethics and the ethical lives of clinicians. J Med Pers 8:15-20

4. Giussani L (1997) The religious sense. McGill-Queen's University Press, Montreal \& Kingston, London 